\title{
The effect of autonomic agents on the pupil and the intraocular pressure of eyes treated with dexamethasone
}

\author{
GEORGE L. SPAETH \\ From the Wills Eye Hospital, Thomas Jefferson University, Philadelphia, USA
}

SUMMARY In an attempt to determine the presence or absence of correlation between the intraocular pressure-increasing and pupil-dilating effects of corticosteroids, the effect of topically applied dexamethasone and various autonomic agents has been studied in 12 hospitalised, healthy, young adult volunteers. Dexamethasone caused an average increase of intraocular pressure of $8.8 \mathrm{mmHg}$ and of pupillary diameter of $0.36 \mathrm{mmHg}$; there was no significant correlation between the change in pressure and the change in pupil size. Furthermore, there was no correlation between magnitude of rise of intraocular pressure and miotic effect of methacholine $2.5 \%$, or mydriatic effect of epinephrine $0.1 \%$, or norepinephrine $0.1 \%$. Dexamethasone-treated eyes showed a greater decrease in pupillary diameter in response to methacholine than their untreated mates $(-1.14$ and $-0.68 \mathrm{~mm}$ respectively) and a slightly smaller increase in response to epinephrine than their controls $(-0 \cdot 18$ and -0.53 respectively). Methacholine caused an increase in intraocular pressure of $2.8 \mathrm{mmHg}$ in control eyes and $6.0 \mathrm{mmHg}$ in dexamethasone-treated eyes. Increases of less significance were caused by epinephrine and norepinephrine. Subjects with the largest rise of intraocular pressure in response to dexamethasone also showed the greatest increase in intraocular pressure in response to the autonomic agents and to the water drinking test. Furthermore, they had lower coefficients of aqueous outflow than those having smaller responses. Methacholine $2.5 \%$ produced miosis in over $50 \%$ of normal control eyes.

Dilatation of the pupil occurs in many individuals receiving topical corticosteroids. ${ }^{1}$ An increase of intraocular pressure has also been noted in many of them, but there does not appear to be a correlation between dilatation of the pupil and rise in pressure. ${ }^{2-4}$

The purpose of the present study was to attempt to determine if sensitivity to agents of the sympathetic or parasympathetic nervous system (1) accounts for the pupillary dilatation or (2) plays a role in the increase of intraocular pressure seen in corticosteroid-treated patients.

\section{Materials and methods}

Twelve normal college students ranging in age from 17 to 21 were studied. They were admitted to hospital for the entire duration of the study. The

Correspondence to Dr Spaeth at Wills Eye Hospital, 1601 Spring Garden Street, Philadelphia, PA. 19130, USA. sexes were equally represented. Medical histories were unremarkable; none had signs or symptoms of glaucoma and none knew of any member of his family who had glaucoma. General physical and ocular examinations were normal.

Before administration of any medication intraocular pressures were determined by Goldmann applanation tonometry daily at 7 to 8 o'clock in the morning for at least 1 week, and tonographies were performed with the Mueller Electronic Tonometer. Each time intraocular pressure was measured pupillary diameter was estimated by utilising the scale on the Goldmann perimeter (with standard illumination and with an attempt to keep accommodation uniform).

Before and about 4 weeks after starting dexamethasone $0 \cdot 1 \%, 5$ times a day in one eye, the responsiveness of the pupil and the intraocular pressure to various autonomic nervous system drugs was tested. Epinephrine $0.1 \%$, norepinephrine $0.1 \%$, and methacholine $2.5 \%$ were employed. One 
drop of the medication being tested was instilled in both eyes, and pupil size and intraocular pressure were determined every 15 minutes for at least 2 hours. Subsequent measurements were made less frequently for the next 24 hours. Water drinking tests were also done before and about 4 weeks after administration of dexamethasone; tap water was drunk within 5 minutes $(14 \mathrm{ml}$ per $\mathrm{kg})$, and intraocular pressures were determined prior to and at 10 minute intervals for one hour after drinking; all subjects were fasting.

Throughout the study intraocular pressure was measured daily and tonography performed weekly. In some subjects frequency of administration of dexamethasone was decreased when it became apparent that 5 drops a day was producing an excessive rise in intraocular pressure.

\section{Results}

Dexamethasone $0 \cdot 1 \%, 4$ or 5 times a day, produced an average increase of intraocular pressure of $8.8 \mathrm{mmHg}$ (Table 1). There was no significant change in coefficient of aqueous outflow (C) (Table 1). The intraocular pressure and coefficient of aqueous outflow of the untreated eyes did not change significantly (Table 1 ).

Though almost all subjects had a slight increase in the size of the pupil of the dexamethasonetreated eye, this was frequently transient. Average pupil size of treated eyes was $5.20 \mathrm{~mm}$ and untreated eyes $(4.84 \mathrm{~mm}$ (Table 2). There was no correlation between the increase in the size of the pupil caused by the topical dexamethasone and the concurrent rise of intraocular pressure. Ptosis and temporarily blurred vision were noted occasionally, but no serious side effects occurred.

Table 1 Effect of dexamethasone $0 \cdot 1 \%$ on intraocular pressure and coefficient of aqueous outflow in 12 normal volunteers

\begin{tabular}{|c|c|c|c|}
\hline & $\begin{array}{l}\text { Before } \\
\text { treatment }\end{array}$ & $\begin{array}{l}\text { After } 30 \\
\text { days of } \\
\text { treatment }\end{array}$ & $\begin{array}{l}\text { Difference, } \\
\text { pre vs. post }\end{array}$ \\
\hline \multicolumn{4}{|l|}{ Intraocular pressure $(\mathrm{mmHg})$} \\
\hline Untreated eye & $12 \cdot 1$ & $12 \cdot 6$ & $+0 \cdot 5$ \\
\hline Treated eye & $12 \cdot 2$ & $21 \cdot 0$ & $+8 \cdot 8^{*}$ \\
\hline Difference between eyes & $0 \cdot 1$ & $8 \cdot 4$ & $8 \cdot 3 *$ \\
\hline \multicolumn{4}{|c|}{$\begin{array}{l}\text { Coefficient of aqueous outflow } \\
(\mu \mathrm{l} / \mathrm{min} / \mathrm{mmHg})\end{array}$} \\
\hline Untreated eye & $0 \cdot 27$ & $0 \cdot 24$ & -0.03 \\
\hline Treated eye & $0 \cdot 26$ & $0 \cdot 22$ & -0.04 \\
\hline Difference between eyes & 0.01 & 0.02 & 0.01 \\
\hline
\end{tabular}

* Statistically significant difference $(P<0.01)$.
Table 2 Effect of autonomic agents on the pupillary diameter of eyes of normal volunteers treated with dexamethasone in 1 eye

\begin{tabular}{|c|c|c|c|}
\hline & $\begin{array}{l}\text { Before } \\
\text { ANS agent } \\
(\mathrm{mm})\end{array}$ & $\begin{array}{l}\text { After } \\
\text { ANS agent } \\
(\mathrm{mm})\end{array}$ & $\begin{array}{l}\text { Change } \\
(\mathrm{mm})\end{array}$ \\
\hline \multicolumn{4}{|l|}{ Methacholine, $2.5 \%$} \\
\hline Control eye & $4 \cdot 84$ & $4 \cdot 16$ & $-0.68 * *$ \\
\hline Dexamethasone eye & $5 \cdot 14$ & $4 \cdot 00$ & $-1 \cdot 14 *$ \\
\hline \multicolumn{4}{|l|}{ Epinephrine, $0.1 \%$} \\
\hline Control eye & $4 \cdot 74$ & $5 \cdot 27$ & $+0.53 * * *$ \\
\hline Dexamethasone eye & $5 \cdot 25$ & $5 \cdot 43$ & $+0 \cdot 18$ \\
\hline \multicolumn{4}{|l|}{ Norepinephrine, $0.1 \%$} \\
\hline Control eye & 4.93 & $4 \cdot 85$ & -0.08 \\
\hline Dexamethasone eye & $5 \cdot 22$ & $5 \cdot 04$ & $-0 \cdot 18$ \\
\hline \multicolumn{4}{|l|}{ Total } \\
\hline Control eye & $4 \cdot 84$ & & \\
\hline Dexamethasone eye & $5 \cdot 20$ & & \\
\hline Difference between eyes & $0 \cdot 36 * * *$ & & \\
\hline
\end{tabular}

ANS $=$ Autonomic nervous system. *Statistically significant: ${ }^{* P} \leq 0.01$. **P $\leq 0.02$. ***P $\leq 0.05$.

Table 3 Effect of autonomic agents on the intraocular pressure of eyes with dexamethasone

\begin{tabular}{|c|c|c|c|c|}
\hline & $\begin{array}{l}\text { Before } \\
\text { ANS agent } \\
(\mathrm{mmHg})\end{array}$ & $\begin{array}{l}\text { After } \\
\text { ANS agent } \\
(\mathrm{mmHg})\end{array}$ & $\begin{array}{l}\text { Change } \\
(\mathrm{mmHg})\end{array}$ & $\%$ \\
\hline \multicolumn{5}{|l|}{ Methacholine, $2.5 \%$} \\
\hline Control eye & $12 \cdot 3$ & $15 \cdot 1$ & $+2 \cdot 8$ & 23 \\
\hline Dexamethasone eye & $17 \cdot 9$ & $23 \cdot 9$ & $+6 \cdot 0$ & 33 \\
\hline \multicolumn{5}{|l|}{ Epinephrine, $0.1 \%$} \\
\hline Control eye & $11 \cdot 3$ & $12 \cdot 9$ & $+1 \cdot 6$ & 11 \\
\hline Dexamethasone eye & $19 \cdot 8$ & $22 \cdot 2$ & $+2 \cdot 4$ & 13 \\
\hline \multicolumn{5}{|l|}{ Norepinephrine, $0.1 \%$} \\
\hline Control eye & $11 \cdot 6$ & $12 \cdot 6$ & +0.8 & 7 \\
\hline Dexamethasone eye & $20 \cdot 8$ & $22 \cdot 1$ & $+1 \cdot 3$ & 5 \\
\hline
\end{tabular}

ANS $=$ Autonomic nervous system

Administration of several of the autonomic nervous system drugs produced changes in intraocular pressure as well as in pupillary size (Tables 2 and 3). When these alterations were biphasic, both the greatest and the smallest values were recorded and averaged separately in the statistical analysis. The tables include only the predominant changes.

The miotic effect of methacholine $2.5 \%$ was small but definite. $47 \%$ of control eyes had no change in pupil size, $31 \%$ a $1 \mathrm{~mm}$ decrease, $19 \%$ a $2 \mathrm{~mm}$ decrease, and $3 \%$ a $3 \mathrm{~mm}$ decrease. Responsiveness was accentuated by pretreatment with 
Table 4 Effect of methacholine $2.5 \%$ on the pupil

\begin{tabular}{lll}
\hline $\begin{array}{l}\text { Amount of } \\
\text { constriction } \\
(\mathrm{mm})\end{array}$ & $\begin{array}{l}\text { Control eyes (36) } \\
(\%)\end{array}$ & $\begin{array}{l}\text { Dexamethasone- } \\
\text { treated eyes }(12) \\
(\%)\end{array}$ \\
\hline 0 & 47 & 29 \\
1 & 31 & 35 \\
2 & 19 & 29 \\
3 & 3 & 7 \\
\hline
\end{tabular}

dexamethasone (Table 4). Epinephrine $0 \cdot 1 \%$ had a greater mydriatic effect on control eyes than on those treated with dexamethasone. The magnitude of reaction was small in both groups but was statistically significant in the control eyes. Norepinephrine $0.1 \%$ appeared to be without significant effect on the pupil.

None of the untreated subjects showed an increase of intraocular pressure greater than $7 \mathrm{mmHg}$ in response to an oral water load; on the other hand $50 \%$ of eyes treated with dexamethasone had rises greater than $7 \mathrm{mmHg}$.

\section{Discussion}

Greater increases of intraocular pressure in steroidtreated eyes in response to cycloplegics and to water drinking have been noted by others. ${ }^{4-6}$ The effects on the pupil have not, however, been extensively studied. There is some evidence that this effect is not in actuality related to the steroid itself. Newsome and coworkers have noted that mydriasis and ptosis were induced by the vehicle of dexamethasone phosphate (Decadron), but not by dexamethasone in saline. ${ }^{7}$ They also noted a lack of correlation between pupil and lid changes on one hand and rise in pressure on the other. Kern and Macri reported that isolated preparations of sphincter and dilator muscle from monkey eyes showed a greater responsiveness to varying agents when the bathing solution contained the vehicle of steroid drops, but not when it contained the steroid alone. ${ }^{8}$

The results of the present study do not explain the mechanism of dexamethasone-induced dilatation of the pupil. Specifically they do not demonstrate any increased sensitivity to agents of the sympathetic nervous system or a decreased sensitivity to cholinergic stimuli. Indeed there was an inhibition of sympathetic and facilitation of parasympathetic activity. An additional indicator of this lack of relationship between responsiveness of the pupil and sensitivity to autonomic agents is the slightly ptotic lid which is fairly characteristic of patients treated with topical corticosteroids. If increased sensitivity to adrenergic agents were a factor, the upper lid should not be ptotic, but should be retracted owing to stimulation of Mueller's muscle. Previous investigations of the relationship between corticosteroids and the autonomic nervous system indicate that this association is a complex one. ${ }^{9-12}$

The greater responsiveness of the dexamethasonetreated eyes may be a factor of greater drug penetration. The corneal permeability may have been altered by the repeated administration of the steroid drops, either due to the vehicle or the steroid. Baum has shown an increased corneal thickness after topical steroid treatment. ${ }^{13}$

Since Scheie's report that methacholine causes pupillary constriction in patients with Adie's syndrome, it has been generally believed that methacholine $2.5 \%$ is without effect on the pupil of normal individuals. ${ }^{14}$ This was not confirmed in the present study, in which a decrease in pupil size of $2 \mathrm{~mm}$ or greater was noticed in almost onequarter of the control (normal) eyes (Table 4). This responsiveness may be related to the freshness of the solution used, for methacholine is unstable in solution and in the present study was prepared immediately prior to administration.

It was of interest that eyes most sensitive to the ocular hypertensive effect of dexamethasone reacted most markedly to the other tests employed in the present study; they showed the greatest intraocular pressure response to methacholine, epinephrine, norepinephrine, and the water drinking test (Table 5 ). In fact the 3 groups in Table 5 behave differently

Table 5 Effect of various autonomic agents on intraocular pressure, depending on the responsiveness of the eye to the intraocular pressure-inducing effects of dexamethasone: Each group consists of 4 normal volunteers, grouped according to the responsiveness of their intraocular pressure to dexamethasone

\begin{tabular}{|c|c|c|c|}
\hline & $\begin{array}{l}\text { Group } \\
I\end{array}$ & $\begin{array}{l}\text { Group } \\
\text { II }\end{array}$ & $\begin{array}{l}\text { Group } \\
\text { III }\end{array}$ \\
\hline $\begin{array}{l}\text { Rise in intraocular pressure } \\
\quad(\mathrm{mmHg})\end{array}$ & $3 \cdot 3$ & $7 \cdot 8$ & $15 \cdot 5$ \\
\hline $\begin{array}{l}\text { Response to methacholine, } 2.5 \% \\
(\mathrm{mmHg})\end{array}$ & $+5 \cdot 3$ & $+\cdot 3 \cdot 3$ & $+8 \cdot 2$ \\
\hline $\begin{array}{l}\text { Response to epinephrine, } 0.1 \% \\
(\mathrm{mmHg})\end{array}$ & $+2 \cdot 0$ & $+4 \cdot 0$ & $+7 \cdot 8$ \\
\hline $\begin{array}{l}\text { Response to norepinephrine, } 0.1 \% \\
(\mathrm{mmHg})\end{array}$ & $+0 \cdot 3$ & +0.5 & +3.0 \\
\hline $\begin{array}{l}\text { Response to water drinking test } \\
(\mathrm{mmHg})\end{array}$ & & & \\
\hline Before dexamethasone & $+2 \cdot 5$ & $+3 \cdot 0$ & $+2 \cdot 5$ \\
\hline After dexamethasone & $+3 \cdot 0$ & $+6 \cdot 4$ & $+9 \cdot 7$ \\
\hline Change in $\mathrm{C}(\mu \mathrm{l} / \mathrm{min} / \mathrm{mmHg})$ & +0.03 & +0.01 & -0.05 \\
\hline
\end{tabular}


enough from each other to indicate that each group represents a different population from the other 2 . The large increase of pressure induced by methacholine is surprising, especially in view of the usual hypotensive effect of this medication. Dexamethasone-sensitive eyes showed a decrease in coefficient of aqueous outflow which the less reactive eyes did not (Table 5).

This close correlation between the ocular hypertensive effect of dexamethasone and the ocular hypertensive effect of the various autonomic agents forms an intriguing contrast to the lack of relationship between dexamethasone-induced rise in pressure and pupil size and the similar lack of relationship between rise of pressure and sensitivity to the pupillary effects of several autonomic agents. Those eyes sensitive to the intraocular pressure-inducing effect of corticosteroids were also more sensitive to other external (and perhaps internal) stimuli that effect intraocular pressure. As such these eyes may be manifesting what has classically been considered one of the characteristics of the glaucomatous eye.

\section{References}

${ }^{1}$ Armaly MF. Effect of corticosteroids on intraocular pressure and fluid dynamics. Arch Ophthalmol 1964; 71: 636-44.

${ }^{2}$ Spiers F. Topical steroids and intraocular pressure. Acta Ophthalmol 1965; 43: 735-45.
3Miller D, Peczon JD, Whitworth CG. Corticesteroids and functions in the anterior segment of the eye. Am J Ophthalmol 1965; 59: 31-4.

${ }^{4}$ Spaeth GL. Effects of topical dexamethasone on intraocular pressure and the water drinking test. Arch Ophthalmol 1966; 76: 772-83.

${ }^{5}$ Kitazawa Y. On water-drinking tonography in steroidinduced ocular hypertension. Jpn J Ophthalmol 1966; 10: $162-71$.

${ }^{6}$ Harris LS, Galin MA, Mittag TW. Cycloplegic provocative testing after topical administration of steroids. Arch Ophthalmol 1971; 86: 12-4.

${ }^{7}$ Newsome DA, Wong VG, Cameron P, Anderson RR. 'Steroid-induced' mydriasis and ptosis. Invest Ophthalmol 1971; 10: 424-9.

${ }^{8}$ Kern R, Macri FJ. Steroid eye drops and their components: Effect on isolated intraocular muscles of monkeys. Arch Ophthalmol 1967; 78: 794-802.

${ }^{9}$ Torda C, Wolff HG. Effects of adreno-corticotrophic hormone, cortisone-acetate, and 17-hydroxy-corticosterone21-acetate on acetylcholine metabolism. Am J Physiol 1952; 169: 150-8.

${ }^{10}$ Reis DJ. Potentiation of the vasoconstrictor action of topical norepinephrine on the human bulbar conjunctival vessels after topical application of certain adrenocortical hormones. J Clin Endocrinol Metab 1960; 20: 446-56.

${ }^{11}$ Fowler NO, Chou NHF. Potentiation of smooth muscle contraction by adrenal steroids. Circulation Res 1961; 9: 153-6.

${ }^{12}$ van Alphen GW, Robinette SL, Macri FJ. Drug effects on ciliary muscle and choroid preparations in vitro. Arch Ophthalmol 1962; 68: 81-93.

${ }^{13}$ Baum JL. Corneal thickness after topical corticosteroid therapy. Arch Ophthalmol 1968; 79: 366-9.

${ }^{14}$ Scheie HG. Site of disturbance in Adie's syndrome. Arch Ophthalmol 1940: 24: 225-37. 